https://doi.org/10.32735/S0718-220120180004700165

75-89

METADRAMA: REESCRITURAS Y FALSIFICACIONES EN SHAKESPEARE, BARRALES Y RADRIGÁN

Metadrama: Rewritings and Forgeries in Shakespeare, Barrales and Radrigán

\author{
CAROLINA BRNCIĆ BECKER \\ Universidad de Chile \\ carolinabrncic@uchile.cl
}

Resumen

Este artículo aborda dos reescrituras de William Shakespeare en la dramaturgia chilena actual, Shakespeare falsificado: reconstrucción falsificada de un manuscrito censurado (2011) de Luis Barrales y La Tempestad (2015) de Juan Radrigán. Para ello propone la reescritura como ejercicio metadramático, un gesto consciente, dramático y político, que busca dialogar y discutir con el original, inscribiendo la nueva perspectiva autorial en el continuum de la tradición cultural. Dentro de este enfoque, el trabajo expone, en primer lugar, las características de la dramaturgia renacentista inglesa como una praxis híbrida, colaborativa, refundidora y política. Luego, caracteriza ambas reescrituras como prácticas que muestran la vigencia y continuación de un canon cultural, literario y dramático, por medio de las distintas modulaciones que se imprimen desde estas nuevas voces. Asimismo, las perspectivas de Barrales y Radrigán se exhiben como gestos políticos expresados hacia sus contextos.

Palabras clave: William Shakespeare; Luis Barrales; Juan Radrigán; metadrama; reescritura; teatro político.

Abstract

The following article approaches two rewritings of William Shakespeare's work within current Chilean playwriting: Shakespeare falsificado: reconstrucción falsificada de un manuscrito censurado (2011), by Luis Barrales and La Tempestad (2015), by Juan Radrigán. It proposes rewriting as a metadramatic exercise, a conscious gesture -both political and dramatic- that seeks to establish dialogue and discussion with its original, inscribing a new authorial perspective within the cultural tradition continuum. With this approach, this work exposes, first, characteristics from English renaissance dramaturgy as a hybrid praxis, collaborative, refounding and political. Then, it characterises both rewritings as practice that showcase the currency and continuation of a cultural, literary and dramatic canon through different articulations that print themselves in our voices. Likewise, Barrales and Radrigan's perspectives display themselves as political gestures expressed towards their contexts.

Key words: William Shakespeare; Luis Barrales; Juan Radrigán; metadrama; rewriting; political theatre. 
Reescrituras y falsificaciones nos inscriben en el problema de la autoría y de los textos llamados originales, así como en el de sus distintas modulaciones y versiones, en el de las diferentes perspectivas frente a un argumento que la tradición canoniza como la obra original.

En el desarrollo de la escena chilena de los últimos quince años llama la atención la irrupción de múltiples dramaturgos que recuperan argumentos de la tradición dramática clásica, particularmente del acervo griego y del teatro renacentista inglés, en especial del corpus shakespereano ${ }^{1}$. En algunas reescrituras asombra, por una parte, la reducción y jibarización de los textos y argumentos, siendo en muchos casos reconocibles únicamente a partir del nombre del personaje que moviliza la acción o bien que da el título a la pieza. Es posible entonces preguntarse qué anima a estos escritores a recuperar esas fábulas en detrimento de creaciones originales. Si se trata de un ejercicio que busca mantener viva la tradición en su validación o apropiación y superación, si las preguntas, temas y problemas que animaron esas piezas siguen vigentes y se modulan en una lengua y lenguaje diferentes, manteniendo de esa manera un canon y una memoria literaria; o bien, si en el caso particular del teatro y la dramaturgia se hace necesario recuperar esos materiales para seguir hablando, en la idea de Heiner Müller (2001), del teatro como crisis que recupera y transforma, o en la concepción de Samuel Beckett (2006) para quien siempre hablamos palabras ya dichas por otros personajes/autores dramáticos ${ }^{2}$.

Sea cual fuere la respuesta desde la intencionalidad que tiene este gesto en cada dramaturgo en particular, nos encontramos frente a lo que Richard Hornby (1996) denominó como metadrama, es decir, la confirmación de que toda materia del drama es el complejo drama/ cultura, entendido este como la intersección del drama como

\footnotetext{
${ }^{1}$ En el caso de las reescrituras griegas encontramos las piezas de Benjamín Galemiri Edipo asesor (2000) e Infamante Electra (2005), Medea mapuche (2000) de Juan Radrigán, Ulises o no (2006) de Benito Escobar, las obras de Ana López Montaner El thriller de Antígona (2006) y Medea o la desesperada conquista del fraude (2006), El clownplejo de Edipo (2009) de Rolando Jara, e Ismene (2010) de Lucía de la Maza (Las tres últimas sin publicar).

En el caso de las reescrituras chilenas shakespeareanas, estas se remontan a la obra Ofelia o la madre muerta (1994) de Marco Antonio de la Parra, la reconocida y paradigmática Lear: rey \& mendigo (2004) de Nicanor Parra, la reescritura de Richard III en Que no quede ni un rescoldo (2013) de Eduardo Pavez, Fortimbrás (2012) de Gerardo Oettinger, Shakespeare falsificado (2011) de Luis Barrales, La Tempestad (2015) de Juan Radrigán, estas últimas tres aún no publicadas. Es importante mencionar dos ejercicios particulares, el de Karen Bauer en Reinas de Shakespeare (2014) con la compañía Teatro Serendipia, pieza original inspirada en las heroínas del autor inglés pero que incorpora pasajes literales de algunas obras de Shakespeare; y la versión folclórica de Sueño de una noche de verano (2015), con la dramaturgia de Héctor Noguera y Daniel Muñoz y la versificación rimada por los payadores Manuel Sánchez y Guillermo 'Bigote' Villalobos. Ambos ejercicios teatrales no han sido publicados.

${ }^{2}$ Atraigo esta última referencia en particular por la pródiga intertextualidad entre el drama beckettiano y shakespereano, verificable en las múltiples citas que pueblan su obra: baste mencionar los parafraseos en Fin de partida de Othello, Hamlet, Richard III y la emblemática cita de Calibán de The Tempest en la afirmación irónica de Clov "Empleo las palabras que me has enseñado. Si ya no significan nada, enséñame otras. O deja que me calle".
} 
sistema con otros sistemas de la literatura, de la performance no literaria, de otras formas artísticas y de la cultura en general. Asumiendo esta premisa, todo dramaturgo está haciendo referencia expresa o implícita a su conocimiento del drama como convención y tradición, de la misma manera en que el espectador es consciente de dicho diálogo. Para el crítico, todo drama es metadramático porque una obra efectiva no es sobre la vida sino sobre el drama mismo (Hornby, 1996, p. 19).

En la historia del teatro, particularmente en el caso griego y renacentista, la relación entre un original y sus versiones constituye el punto de partida para la creación dramática y no una limitación - esto en parte, porque la noción de originalidad es una invención que debemos a los escritores románticos ${ }^{-}$. En la tragedia ateniense el sustrato que da origen a los argumentos trágicos se remonta al mito de las edades oscura y arcaica que se amplifica en las variadas versiones que circulan con los siglos y que se materializan en las distintas modulaciones que realizan los tragediógrafos de un repertorio acotado de fábulas.

En el caso de la dramaturgia renacentista inglesa, la originalidad se difumina en una praxis de larga data que descansa todavía sobre dos pilares fundamentales: la imitatio y la adaptación. Séneca, Terencio y Plauto se convierten en los modelos a seguir para los poetas universitarios y los autores autodidactas, aun cuando ya esos paradigmas ingresan en la tradición inglesa deformados por la adaptación que de ellos hicieran los italianos en una vertiente más escénica y teatral. De esta suerte, se componen tragedias, comedias, dramas históricos y romances al modo de los antiguos, recuperando argumentos, estructuras y estilos de la tradición antigua pero pasados por el tamiz italiano que introduce la variable del espectáculo buscando cautivar al espectador con un montaje más complejo y elaborado desde la escenificación. A ello se suma las posibilidades escénicas que ofrecen los nuevos teatros acondicionados y aquellos especialmente construidos para un heterogéneo público inglés que asiste a los teatros públicos, privados y de corte y que se caracteriza por la diversidad de intereses y gustos. En este marco de una escena teatral que crece vertiginosamente con la creación de nuevos teatros, de un público que consume las diversas producciones y de un grupo importante de dramaturgos -Kyd, Marlowe, Lily, Peele, Lodge, Nashe, Dekker, Shakespeare, Middleton, Wilkins, Fletcher, Webster, Jonson, Chapman- que coincide en una época y alimenta los intereses literarios, de entretención y discusión, el teatro se vuelve punto de reunión y por extensión, un punto de hablada y modulación frente al pasado y el presente, frente a la tradición literaria y dramática y a la contingencia política, religiosa y cultural. Es en este lugar de la enunciación en que diversos sustratos nutren la creación dramática mediante argumentos de distinta procedencia: las crónicas históricas inglesas y romanas, tragedias y comedias latinas, moralidades y misterios medievales, fábulas novelescas italianas, entre otras. De esta suerte, la creación no descansa en la originalidad o novedad de un argumento, sino por la praxis de impronta medieval que concibe la escritura como adaptación y refundición. En el ejercicio de estos préstamos, la autoría como concepto moderno también se desdibuja y falsifica por 
medio de distintas prácticas: en las composiciones a cuatro manos, por ejemplo en la colaboración de George Peele, Thomas Middleton y Thomas Nashe a las obras de Shakespeare en Titus Andronicus, Timon of Athens y Henry VI, respectivamente; en obras atribuidas a dramaturgos que habrían sido escritas por otros, el caso de Eduard III de Shakespeare cuya autoría correspondería a Marlowe como propone el trabajo filológico y estilístico de la crítica marlowiana; y en las falsificaciones de identidades -el fraude autorial de Thomas Nashe quien tras su destierro de Londres asume la falsa identidad y seudónimo de Thomas Dekker para publicar y montar sus obras- (ver Morgan en Murphy, p. xvii ss. y Murphy, p. 3 ss. $)^{3}$.

Por otra parte, los préstamos se exhiben también de forma implícita y explícita en textos híbridos que contienen citas, alusiones, parafraseos y parodias de textos de la tradición antigua pero también de su propia época - muchos de ellos que hoy cabría llamar plagios $^{-}$, que el espectador reconoce ampliamente, en parte, porque el teatro constituye una forma de enciclopedia literaria que educa al público, así como una plataforma de discusión que problematiza las ideas de su época. Para ello, solo algunos ejemplos.

El argumento de Hamlet (1603) de Shakespeare, cuyas raíces se remontan a la historia de Amleth, príncipe de Dinamarca, está registrada en la Gesta Danorum de Saxo Gramaticus de 1185, ampliada en las Histoires tragiqués de Bellesforest y elaborada dramáticamente también por Thomas Kyd en The Spanish Tragedy (1587) ${ }^{4}$.

$\mathrm{O}$ bien, la profusión de citas bíblicas desperdigadas en muchas de las obras dramáticas, que resuenan significativa y problemáticamente en el contexto de la Reforma Anglicana en Inglaterra en la discusión de la doctrina y del texto sagrado. La inclusión de estas citas permite al teatro renacentista dialogar con la tradición dramática inmediatamente anterior, construyendo así un canon dramático-teatral nacional que el público identifica. En ese doble horizonte se inscriben también las profusas alusiones de Marlowe en The tragical history of Doctor Faustus a las nociones de libre albedrío y determinismo desarrolladas por Pico della Mirandola en el "Discurso sobre la dignidad del hombre" y también elaboradas dramáticamente en las moralities y mistery plays de la tradición medieval.

En una línea distinta, el caso de Ben Jonson quien en sus prólogos, en especial a Every Man in his Humour, defiende su concepción de una comedia de humores y sátira, autoinvistiéndose en heredero directo de la tradición clásica y particularmente de Plauto, al exhibir las debilidades humanas y no crímenes para desenmascarar los vicios y enfermedades sociales en un claro ataque frontal a la comedia cortesana cultivada por Shakespeare. O bien, en la expresa exhibición en el acto III de Volpone de sus

\footnotetext{
${ }^{3}$ Acerca del problema de la autoría y colaboraciones en el drama renacentista inglés, véase Donna Murphy The Marlowe Shakespeare Continuum (2013) y James Shapiro Contested Will: Who wrote Shakespeare (2010).

${ }^{4}$ El argumento y texto completo sobre la "Historia de Hamlet" de las Histoires Tragiqués de François de Bellesforest se encuentra disponible en Internet Shakespeare Editions: http://internetshakespeare.uvic.ca/doc/ Belleforest_M/complete/ 
conocimientos de los clásicos -Ovidio y Catulo- y de los renacentistas italianos Dante, Petrarca, Tasso, Guarini, Ariosto, Aretino-.

Finalmente, y como uno de los ejemplos paradigmáticos de este profuso entramado intertextual, The Tempest (1610) de Shakespeare: un argumento que tiene su raíz en el histórico naufragio del Sea Venture en 1609, que despliega la imagen de un mundo nuevo-otro presente en el imaginario colectivo a propósito de las crónicas de viaje de Antonio Pigaffeta traducidas al inglés en 1577, que incluye citas del ensayo de Montaigne "De los caníbales", alusiones a Dido -que bien pueden remitir a Heroidas de Ovidio como a la pieza Dido, Queen of Carthage de Marlowe-, la alusión a No-body and Some-body comedia anónima de 1606, entre otros.

Esta profusa relación intertextual muestra cómo se construye un nuevo repertorio literario dramático nacional en un diálogo expreso con la tradición y con la contemporaneidad, donde el destinatario es tanto el público culto y el popular que reconoce alusiones y referencias, como también el grupo de escritores que se ve incorporado por medio de citas que muchas veces son ironizadas o parodiadas al interior de las obras. De esta suerte, cada obra se integra a una red de composición literaria y dramática y constituye parte de un corpus que puede leerse como una metapoética del teatro renacentista inglés, tejido que exhibe las diferentes poéticas autoriales como posiciones literarias que, en muchos casos, son políticas. Destaco esta dimensión, aspecto que recogeré más adelante, porque el drama político como caracteriza Margot Heinemann (1990) a la dramaturgia isabelina y jacobeana, se convierte en una escena y arena en donde la huella autorial define una posición frente a la literatura, al teatro y al contexto. Es decir, cómo los dramaturgos hablan desde sus textos acerca de la realidad contingente y la impronta que en ella puede ejercer el teatro como gesto, ficción y re-creación o falsificación de la realidad.

Considero relevante tener a la vista los aspectos ya reseñados de la creación renacentista para abordar el problema de las reescrituras de Shakespeare en dos piezas chilenas contemporáneas: Shakespeare falsificado: reconstrucción falsificada de un manuscrito censurado de Luis Barrales y La Tempestad de Juan Radrigán. Esto, porque como ya hemos indicado, una reescritura se inscribe necesariamente en el campo de la metaliteratura, donde la posición autorial se manifiesta como un gesto frente a un original que se modula, deforma e inclusive falsifica. Y esta actitud nunca es inocente. Así lo declara Luis Barrales ya desde el título de su obra Shakespeare falsificado: reconstrucción falsificada de un manuscrito censurado $(2011)^{5}$.

El título nos entrega las claves relevantes para acercarnos a la obra: en primer lugar, la oposición entre verdadero y falso que necesariamente se vincula con la noción de

\footnotetext{
${ }^{5}$ Shakespeare falsificado: reconstrucción falsificada de un manuscrito censurado fue estrenada en Matucana 100, en marzo del 2011. Para mayores referencias acerca de la intención del autor para escribir y montar esta pieza, así como para ver algunas imágenes, ver Entrevista Luis Barrales/Shakespeare Falsificado/M100 https://www.youtube.com/watch?v=P5FQ0nKf-8Y
} 
original y sus versiones o deformaciones. Desde allí, la reconstrucción como ejercicio imaginativo y tentativo, por cuanto se presenta de facto como aproximación fallada - no es el original- y al mismo tiempo, falsificada, exhibiendo su intención consciente y deformatoria frente al supuesto texto inédito. Supuesto, como sugiere el título, porque el manuscrito en su inscripción primigenia ya está afecto a una manipulación impuesta por un organismo censor que mutila la hipotética intención autorial.

Esta dimensión se intenciona y refuerza en el prólogo ad spectatores en boca del autor Shakespeare, personaje que debe mostrarse "como si fuese un fantasma de sí mismo". Como simulacro del original, el poeta se confiesa al público: aduce la existencia de un Macbeth anterior, escrito supuestamente en 1603, año en que muere Isabel I y asume Jacobo I, quien habría censurado el manuscrito ordenando su reescritura en pro de su beneficio. Como el oficio del poeta es el cinismo y su tarea hacerse cínico a sí mismo, este falso dramaturgo - espejeo y desdoblamiento a su vez del dramaturgo Barrales- se propone cantar la verdad: "la falsa historia hablada al revés en fina lengua torpemente encriptada", esto es, en la lengua cervantina con verso blanco perforado por chilenismos.

El juego entre original y falsificación y entre verdad y ficción no es nuevo ni en la dramaturgia shakespereana ni en la poética de Barrales. Recordemos que el Macbeth de 1606 es ya una segunda ficcionalización; la primera corresponde a las Crónicas de Holinshed que versionan -amplifican poéticamente- los hechos de la historia verdadera de Escocia. En Holinshed, Macbeth es un guerrero ilustre que se hace rey a sí mismo, mientras que Banquo es un personaje accesorio. En la amplificación shakespeareana, el autor pone especial énfasis en no presentar a Banquo como conspirador en tanto será tronco de reyes, antecesor directo de Jacobo I, aspecto relevante por cuanto el autor compone la tragedia para la compañía del patrón del rey. Además, la pureza y autenticidad del manuscrito shakespeareano original no sería tal, por cuanto se han comprobado algunas interpolaciones y adaptaciones hechas por Thomas Middleton ${ }^{6}$.

Por otra parte, el juego y los guiños entre verdad y ficción son una estrategia utilizada por Barrales en otra obra, $H P$, en que reconstruye por medio del montaje dramático y teatral no el hecho histórico del crimen de Hans Pozo, sino la ficcionalización fragmentaria que los medios de comunicación hicieron de esa historia. De manera similar ocurre con las estrategias utilizadas en Shakespeare falsificado en la disposición y montaje de las dos secuencias que organizan la obra. La primera corresponde al argumento de Macbeth que nosotros conocemos como la creación original de Shakespeare, para Barrales, el fraude. En ella reconocemos la línea secuencial de los acontecimientos: la profecía a Macbeth, la instigación de Lady Macbeth, el asesinato de Duncan, la instalación como nuevo rey, la persecución y exilio de los nobles, el suicidio de Lady Macbeth y el ajusticiamiento del héroe villano.

Paralelamente esta línea argumental se ve interrumpida sucesivamente por las interescenas en que lo actores discuten cómo dar forma a los acontecimientos y al

\footnotetext{
${ }^{6}$ Acerca de las interpolaciones y adaptaciones en Macbeth, véase Graham Holderness, 2003, pp.170-171.
} 
mismo tiempo cómo reescribir los antiguos personajes y con ello el argumento y desenlace ${ }^{7}$. Estos quiebres y suspensiones de la ilusión dramática que ya ha sido puesta en entredicho desde la ironía de la falsificación y el fraude, pueden leerse como una estrategia reflexiva, por cuanto exhibe cómo se va realizando la reescritura, cómo se actualiza y concreta dramática y escénicamente la modulación de la lectura del original así como de la misma falsificación, vale decir, de la nueva perspectiva. Con ello se busca insistir por una parte en cómo se hace hablar a estos textos canónicos en una nueva realidad, pero también el sentido que esta recuperación/reescritura y falsificación tendría en un contexto contemporáneo y chileno.

Por ello, más allá de hacer al paria un héroe por supuestas órdenes reales como declara el Shakespeare ficcionalizado del prólogo, en estas interescenas son los actores chilenos de la Compañía Central de Inteligencia Teatral los que reescriben el carácter de los personajes, la acción dramática y su desenlace. Así, este nuevo y original Macbeth, es una suerte de Edipo que desconoce sus orígenes, un huacho, fruto de la violación de un noble a una campesina, que derroca una tiranía de diecisiete años y que movido ya no por la ambición sino por la reparación de un orden injusto, lidera la Revolución del pueblo - esa que repartirá los latifundios entre los campesinos en partes iguales, esa que de Revolución pasa a revuelta- para terminar siendo un Macbeth mujer. El personaje se va desdoblando, transformando y con ello falsificando ante los ojos de los espectadores: Macbeth general -Macbeth huacho- Macbeth rey -Macbeth mujer- para espejearse también en Macbeth Pinochet.

Idéntico proceso al de Banquo, que de personaje secundario que muere en el tercer acto en Shakespeare, pasa en esta versión falsificada primero a legitimarse como genuino antecesor de Jacobo I, para luego desdoblarse y asumir el insidioso rol que Yago tiene en Otelo y también mostrarse a como el milico, identificado como el Guatón Romo (agente de la DINA -Dirección de Inteligencia Nacional- durante la dictadura militar) que lidera la masacre y violación de las mujeres campesinas escocesas en pro de este nuevo orden regido por Macbeth Pinochet.

El texto de Barrales se desdobla así en diferentes niveles de actualización y lectura que se friccionan:

Primero, en la línea argumental del texto que nosotros conocemos: el supuesto fraude shakespereano.

Segundo, en la falsificación del manuscrito original que Barrales perfora con múltiples intertextos reconocibles para el lector/espectador de Shakespeare: parafraseos de Macbeth -el ambiguo "lo bello es feo y lo feo es bello"-, de King Lear "Y ahora, a

\footnotetext{
${ }^{7}$ Esta estrategia metadramática y metateatral es de larga data en el teatro contemporáneo y la vemos prolíficamente en la dramaturgia chilena en las poéticas de Ramón Griffero, Guillermo Calderón, y en la misma $H P$ de Barrales recién referida, entre otros. Pero también está presente en la dramaturgia shakespereana si pensamos por ejemplo en Sueño de una noche de verano donde los artesanos -actores aficionados- que darán vida a una representación de Píramo y Tisbe, discuten de la verosimilitud en la representación y cómo resolver escénicamente ciertas complejidades que presenta el argumento.
} 
pesar de mis arrugas, me siento como en la infancia", de Yago en Otelo "Ya está controlado, mi obrar ha sido perfecto/ No distingue Macbeth lo que es falso de lo cierto" y de Hamlet al final. Con ello, espejea las prácticas de los dramaturgos renacentistas.

Tercero, en las alusiones directas a la realidad chilena en la expresión "los ricos también lloran", referencia paródica a la teleserie mexicana exhibida en Chile durante los 80 que contemporiza además la noción de tragedia como la caída de un personaje noble anclándola en la caída de Macbeth-Pinochet; o en la profesión de fe militar "Juro por nuestra bandera que sabré cumplir con mi deber" -resonancia irónica al deber de los militares que mataron campesinos y violaron a las mujeres-, pero también las alusiones indirectas a la reforma agraria, la revolución latinoamericana y socialista, la dictadura, los gobiernos concertacionistas, la lucha de clases y de géneros.

En la perforación del texto en esta multiplicidad de citas y alusiones así como en el desdoblamiento de niveles de ficcionalización -el fraude del Macbeth que conocemos, el de los actores que comentan, el de los actores actuando el nuevo/original pero falsificado Macbeth que es la creación de ellos (y por supuesto de Barrales), el de un narrador que comenta la extraescena de matanza y violación de campesinas que retrotrae al pasado chileno de allanamientos- la obra se nos muestra como una parodia en el sentido que propone Linda Hutcheon, "como transcontextualización e inversión irónica, repetición con diferencia” (Hutcheon, 1985, p. 31-32).

Las reescrituras y falsificaciones siguen poniendo de relieve cómo hablar o cómo hablar de nuevo de los mismos problemas. Así se manifiesta en la última interescena en el diálogo de los actores "que miran consternados la escena que ellos mismos contruyeron", es decir, el original falsificado, sumando además la última parodia en el intertexto de Hamlet:

TAIRA: Le dimos motivos a Macbeth para que ansiara la libertad, aunque en vez de motivos fueron engaños de verdad. Le mentimos, lo manipulamos, lo hicimos ser bastardo y un huacho adoptado. Lo dejamos preso y sin libertad de acción, imponiéndole deseos pero no motivación. Lo negamos de un principio. Ni una fe. $\mathrm{Ni}$ siquiera le opusimos a la Nobleza. Fueron los propios pobres los que no lo dejaron hacer. $\mathrm{O}$ una idea por sobre los pobres. Una idea que ya en 1500 resultaba añeja. Querer todo de golpe, sin sentido del real, pensando por los pobres sin ser pobre en verdad. De los Nobles hubiese esperado Macbeth todo el rencor, no que el mismo pobre hubiese sido el traidor, ahí del fracaso tenimos la razón y chupemos la que cuelga con la Revolución. Prometimos darle voz a los sirvientes, las mujeres y los pobres y terminó en otra tragedia donde los héroes son los nobles.

ACTRIZ 3: ¿Qué se puede hacer?

ACTOR 2: ¿Morir. Dormir?

(Pausa)

SOTO: ¿Intentémoslo con Hamlet? ¡Hacer o no hacer: he ahí la respuesta! ¿Qué vale más para el espíritu: sufrir los golpes del orden mundial o tomar la espada y enfrentar un piélago de multinacionales? (...) ¡Morir..., dormir; no más! ¡no más consumir! Morir, destruir, porque solo destruyendo se hará libre el hombre. Destruir todo y abran los ojos y desencajen las quijadas y tensen el cuello y aprieten el chico. 
Todo. Hacer cataplúm hasta la belleza porque es belleza el photoshop ¡Porque he ahí el problema! Destruir. El resto es teatro (Barrales, 2011, pp. 48-49). ${ }^{8}$

Esta última parodia, falsificación ya no de Macbeth sino de Hamlet, un tanto burda en su explicitación, puede leerse como el gesto autoirónico por excelencia de un metadrama. Al retomar la pregunta hamletiana por la naturaleza, alcances y propósitos de la acción dramática y de la acción teatral en el teatro mismo, Matucana 100, se articula una reflexión de naturaleza dramática y política: qué sentido y resonancias pueden tener los clásicos en la escena chilena contemporánea, su reescritura y también una falsificación o deformación. No es casual que en esta misma parodia resuene otro Hamlet, el de Heiner Müller, Hamletmaschine, en su necesidad de crear sobre las ruinas, asumiendo el teatro como crisis, incesante transformación. Si la globalización trae la virtualidad de una belleza photoshopeada que deforma y destruye el original, la falsificación en el teatro se advierte como praxis que espejea haciendo explícito el original y a su lado, tal como en las interescenas, la nueva modulación o perspectiva autorial en un gesto que nunca es inocente, que no es exclusivamente literario y dramático, sino además político: apelar, remover y no anestesiar al espectador.

Distinto es el caso de Juan Radrigán. Tanto en el texto como en el afiche de la puesta en escena se explicita que esta Tempestad es la versión de Radrigán. Gesto significativo en tanto implica expresamente la marca autorial que define un horizonte de expectativas para el espectador. Ello porque el público chileno asiduo al teatro reconoce en la trayectoria del dramaturgo una poética compositiva en la que es posible identificar temas y preocupaciones constantes en torno a la justicia social, la marginalidad vinculada a la opresión, la soledad y el abandono, entre otros. Claramente el repertorio temático por él desarrollado ha llevado a identificarlo como un escritor comprometido con el contexto nacional, con un posicionamiento político expresamente declarado. Desde allí es posible también identificar su dramaturgia como un teatro de tesis que se expone en ocasiones dialécticamente en torno a binomios de ideas. Como ocurre también en su Tempestad.

Considero relevante el hecho de que se consigne que sea una versión, en tanto el término remite en su origen etimológico a la transformación y a la traducción. Esta última en sus múltiples acepciones y orientaciones conlleva la marca de dos caminos distintos: el de la infidelidad con el modelo (la tradición francesa de las bellas infieles) o bien el de la hospitalidad con el extranjero, propia de la tradición romántica alemana que, es factible señalar además, fue la primera en traducir a Shakespeare en el

\footnotetext{
${ }^{8}$ Ver con el monólogo de Hamlet de Shakespeare: "To be or not to be, that is the question:/ Whether "tis nobler in the mind to suffer/ The slings and arrows of outrageos fortune,/ Or to take arms against a sea of troubles,/ And by opposing, end them. To die, to sleep-/ No more, and by a sleep to say we end/ The heartache and the thousand natural shocks/That flesh is heir to- 'tis a consummation/ Devoutly to be wished. To die, to sleep. To sleep, perchance to dream. Ay, there's the rub,/ For in that sleep of death what dreams may come/ When we have shuffled off this mortal coil/ Must give us pause. (III, 1 lines 58- 70; Shakespeare, 2005, pp. 697-698)
} 
continente europeo. Esta orientación hospitalitaria, permite que el original sea acogido, renovándolo y potenciándolo en el decir de Friedrich Schlegel, augurando su sobrevida.

La elección y ejercicio de Radrigán se inscribe en medio de estas dos vías, al acoger el original prácticamente íntegro en su argumento y discurso dramático, pero reduciéndolo en aras de una concentración y focalización, en la eliminación de algunos personajes y escenas secundarias. Se prescinde por ejemplo de personajes como Sebastián, Gonzalo, Adrián, Francisco, Trínculo y Stefano. Se pierde la escena inicial de la tormenta que en esta versión es referida exclusivamente por Próspero y Ariel, eliminando con ello la perspectiva 'más amplia' del mundo dramático que presenta Shakespeare. Con ello, en Radrigán el mundo nos es mostrado casi binariamente desde la oposición Próspero/Calibán, dándole un protagonismo a este último que en la pieza shakespereana no tiene pero que es una marca de las diferentes recepciones de $L a$ tempestad en América Central y del Sur. En Radrigán pierde fuerza la oposición entre espiritualidad-artificio que caracteriza a Ariel en contraposición a la materialidadrusticidad que retrata a Calibán, para ser reemplazada por el binomio Próspero/Calibán. En la pieza chilena es Calibán el verdadero antagonista de Próspero, razón por la que se suprimen las escenas cómicas entre él, Stefano y Trínculo que menoscaban la representación seria del salvaje para relevar la oposición entre opresor/oprimido, conquistador/conquistado, verdugo/víctima, que permite a su vez enfatizar no solo la oposición entre Europa/América (perspectiva realzada en casi todas las recepciones latinoamericanas de la pieza), sino además las referencias al contexto chileno, el régimen de la dictadura y los gobiernos de la Concertación. Si bien persiste la condición del otro, esta ya no es la del salvaje, sino más bien la del oprimido y torturado que se refleja en un discurso de la violencia, enunciado desde la violencia. Lo interesante es que este rasgo de la enunciación no queda capturado exclusivamente en el personaje de Calibán sino que también es propio de Próspero, como veremos.

La concentración del argumento y la reducción condensada del discurso dramático permite que se esbocen nítidamente las dos voces autoriales: la de Shakespeare y la de Radrigán y con ello las perspectivas que los determinan. Hay, podría decirse, una actitud más seria en Radrigán frente al original -ejercicio que ya había realizado en su versión del clásico de Eurípides con su Medea mapuche-, en parte porque el autor es mucho más proclive a un teatro de tesis y menos experimental en sus artilugios dramáticos y teatrales, a diferencia de Barrales ${ }^{10}$. Pese a ello, se permite un solo guiño metadramático en boca de Próspero que me parece significativo:

\footnotetext{
${ }^{9}$ Me refiero fundamentalmente a la reflexión teórica de Roberto Fernández Retamar en su ensayo de 1971 “Calibán” y otros reunidos en Todo Calibán (1998) y a las reescrituras de Aimé Césaire Une tempête (1969) y de Augusto Boal A tempestade (1974).

${ }^{10}$ Esta diferencia no instala a Radrigán y Barrales en dos concepciones dramáticas y teatrales diferentes. Muy por el contrario, Radrigán fue maestro de Barrales y este se reconoce como uno de sus herederos, aun cuando en su dramaturgia es mucho más explícita la búsqueda de nuevas expresiones y estrategias dramáticas y teatrales, en clara consonancia también con parte de las características de la generación de dramaturgos chilenos que inician su producción en el segundo milenio.
} 
Próspero: No te pongas melodramático, déjalo eso a Shakespeare.

Ariel: ¿Quién es ese?

Próspero: El culpable de que estemos en esto.

Ariel: ¿Está en la isla?

Próspero: No; es un genio, pero a veces suele tirar la piedra y esconder la mano.

Ariel: Como tú.

Próspero: No me ofendas, no tienes jerarquía para hacerlo. Pero no respondas, la escena debe continuar (p. 30).

A diferencia de las interescenas de Barrales que suspenden y fragmentan la ilusión dramática, este es el único pasaje en Radrigán en que hay una giro metadramático, en que la versión se pliega e ironiza el original. Dos aspectos a relevar en esta ironía: las menciones al melodrama y a la hipocresía del dramaturgo isabelino vinculadas a la naturaleza de la acción y del desenlace.

En la perspectiva de Radrigán, la tibieza de Shakespeare estaría en la forma de resolver el conflicto dramático que aborda los mismos problemas que él toca: el poder, la traición y el olvido. La amargura, el rencor y los deseos de venganza del Próspero shakespereano relatando a Miranda la traición y el exilio en el primer acto, contrastan con la actitud conciliatoria del quinto acto al perdonar a los enemigos luego de los artilugios por él dispuestos. En Radrigán, el exduque de Milán conserva las características de su antecesor, al punto que cuando se describe a sí mismo y la vejación que ha sufrido, es una cita del original, una traducción literal (I, 2). Estudioso, mago, déspota y autoritario, se ha convertido ahora en lo mismo que condenaba en sus enemigos. Pero es en este rasgo -y no en el carácter de artífice que tan relevante es en Shakespeare $^{11}$ - donde el autor chileno se concentra y donde realiza una de las transgresiones más significativas al original y donde se sella su traducción de Shakespeare. En esta versión Próspero es llamado señor y señora por Ariel y como perro y perra por Calibán. La indeterminación genérica que se potencia en el montaje teatral con la encarnación del personaje en una actriz fuertemente masculinizada en su caracterización, es una alusión directa y enfática al contexto nacional. En particular, a los gobernantes de la dictadura, Concertación y Alianza. La perspectiva autorial insiste en marcar al personaje ambiguamente en una doble condición: su carácter represor y déspota y al mismo tiempo su condición femenina que ahora la convierte en madre de Miranda y no en padre y la lleva a aullar. La perra vencida por los otros, aquella que en las primeras escenas exigía reparación y justicia frente a la otrora usurpación y vejación, muestra su corrupción en el ejercicio del poder al convertirse exactamente en lo que sus oponentes encarnan: una usurpadora, déspota y autoritaria. No en vano será en boca de Calibán en donde resuene la sentencia ni perdón ni olvido amplificando la demanda de

\footnotetext{
${ }^{11}$ Este aspecto es decisivo en la caracterización del Próspero shakespeareano por cuanto da cuenta de la reflexividad de la pieza. Próspero es ante todo un artífice, un prestidigitador de ilusiones, condición que espejea como alter ego al dramaturgo/artífice real, Shakespeare, y que da sentido al epílogo que cierra la obra. Acerca de este aspecto volveremos al final.
} 
los familiares de las víctimas de la dictadura chilena. La ambigüedad e intedeterminación muestra cómo el ejercicio violento del poder lleva a las víctimas a convertirse en victimarios y cómo esta condición es independiente del género o de la adhesión política. Imposible no pensar en esta ambigüedad en la ironía como gesto explícito hacia Michelle Bachelet, hija de general de la Fuerza Aérea, torturado político, víctima por tanto de la dictadura que llega a convertirse en Presidenta de la República y representa, desde la perspectiva autorial, la tibieza de los consensos frente a los opresores.

Radrigán mantiene la resolución conciliatoria del Próspero shakespeareano pero en una versión ironizada tanto del texto inglés como de los discursos políticos chilenos, dejando el epílogo a cargo de Calibán:

Calibán: Se van, se van más deshonrados que enaltecidos.

La perra herida aulló insultos y venganzas, la perra tramó justas represalias.

Pero su casta no resiste

la pérdida del boato y del poder, la traición le cayó encima y perdonó.

El perro perdonó, la perra perdonó; todo fue una colosal faramalla, un cuento de hadas que disfrazó de tragedia.

Todas las humillaciones, todas las heridas, convertidas por su apostasía en azules alegrías.

¡Qué desintegrada integridad, qué simulacro de amor tan perverso!

Se van, madre, se van más trágicos que cuando llegaron.

Que no se cante este canto, si pudieron escribir esta historia fue que antes murieron de vergüenza.

Pongamos, madre, cuatro velas de deshonra en sus cadáveres y mantengámoslas encendidas para siempre. (55)

En Shakespeare en cambio:

Prospero: Now my charms are all o'erthrown, And what strength I have's mine own, Which is most faint. Now 'tis true I must be here confined by you Or sent to Naples. Let me not, Since I have my dukedom got, And pardoned the deciever, dwell In this bare island by your spell; But release me from hands.

Gentle breath of yours my sails Must fill, or else my Project fails, 
Which was to please. Now I want

Spirit to enforce, art to enchant;

And my ending is despair

Unless I be relieved by prayer,

Which pierces so, that it assaults

Mercy itself, and frees all faults.

As you crimes would pardoned be,

Let your indulgence set me free (Epilogue, versos 1-20).

Claramente en ambos epílogos resuena la perspectiva autorial de Radrigán y Shakespeare, respectivamente, y con ello el rol de los dramaturgos en sus contextos de producción. La explícita posición política de Radrigán alineada con las víctimas de la opresión y dictadura encarnadas en Calibán, refuerzan su emplazamiento crítico al discurso político del consenso representado tanto por la derecha como por la Concertación. Así, la indeterminación en la caracterización de Próspero como perro y perra al mismo tiempo, muestra cómo el ejercicio del poder en Chile, independiente del género, se hace eco del olvido, manteniendo las heridas abiertas.

Me parece importante concluir con una rehabilitación del rol del dramaturgo en la Tempestad shakespereana, precisamente para poner en contexto la dimensión de un teatro político. Claramente Próspero es una suerte de espejeo del propio dramaturgo isabelino, al disponer varios elementos ilusorios para lograr un fin. Como él mismo señala en el epílogo, su arte es el de encantar, lo que no implica un divertimento de corte evasionista como las fantasmagorías e ilusiones de Sueño de una noche de verano. Se ha logrado comprobar que La tempestad de 1616 fue una obra representada en un teatro de corte y no en uno público, lo que implica entre otras cosas, un público distinto en un contexto epocal en que la abierta dimensión cuestionadora del teatro está siendo arrinconada -como lo demuestra la producción dramática de otros autores bajo el reinado de Jacobo I-. Por otra parte, las convenciones de los géneros dramáticos siguen vigentes y para el caso de los romances, como se clasifica a la Tempestad -y no una tragedia disfrazada de cuento de hadas como propone Radrigán-, el fin conciliatorio es regla. De la misma manera en que la tragedia renacentista concluye con la implantación de un nuevo orden y la comedia con la vuelta a la naturalidad tras la inversión total, en cada uno de estos géneros la subversión no está en el tour de force de un desenlace confrontacional y directo. Muy por el contrario, la subversión y con ello la discusión y problematización se expone en el modo y forma en que se dispone el desarrollo dramático. De allí que pese a la censura, la discusión respecto de las prácticas contextuales estén expuestas, pero no explicitadas como teatro de tesis, moralizante, didáctico o ideológico. Para eso está la corte, el Parlamento y los distintos escenarios performáticos de la City. Por ello, retomo irónicamente el parlamento final de Barrales: "El resto es teatro" y en él se instala el gesto político, dramática y teatralmente, para quien quiera verlo y escucharlo. Para los otros "the rest is silence". 
Este artículo es parte de la investigación del proyecto Fondecyt Iniciación $\mathrm{N}^{\circ}$ 11130269 "Estudio de la reflexividad en el drama antiguo y moderno". Agradezco enormemente las autorizaciones de Luis Barrales y Flavia Radrigán para referir las obras Shakespeare falsificado: reconstrucción falsificada de un manuscrito censurado y La tempestad de Juan Radrigán mediante sus manuscritos, piezas estrenadas en el 2011 y 2015, respectivamente, pero aún no publicadas.

\section{OBRAS CITADAS}

Barrales, Luis (2015). HP. En Obras escogidas. 1. Santiago: Eloy Ediciones.

— (2011). Shakespeare falsificado: reconstrucción falsificada de un manuscrito censurado. Manuscrito, aún sin publicar. Autorización del autor.

Beckett, Samuel (2006). Fin de partida. En Teatro reunido. Buenos Aires: Tusquets.

Bellesforest, François (s/f). "The History of Hamlet". En Histoires Tragiqués. Disponible en:http:/internetshakespeare.uvic.ca/doc/Belleforest_M/complete/

Boal, Augusto (2016). La tempestad. En Revista Conjunto $\mathrm{N}^{\circ} 1 \overline{7} 8$. Casa de las Américas, Cuba. Enero-Marzo.

Césaire, Aymé (2011). Una tempestad. Buenos Aires. El 8avo. Loco Ediciones.

Della Mirandola, Giovanni Pico (2007). "Discurso sobre la dignidad del hombre". En Humanismo y Renacimiento. Madrid: Alianza.

De la Parra, Marco Antonio (2010). Ofelia o la madre muerta. Disponible en: Celcit. Dramática latinoamericana 330. www.celcit.org.ar

De Montaigne, Michel (1995). “De los caníbales". Ensayos escogidos. México: UNAM. Fernández, Roberto (1998). Todo Calibán. Concepción: Cuadernos Atenea.

Escobar, Benito (2006). Ulises o no seguida de frontera. Santiago: Editorial Ciertopez.

Galemiri, Benjamín (2007). Edipo asesor. Infamante Electra. En Obras completas I. Santiago: Uqbar.

Heinemann, Margot (1990). "Drama and Society”. En Braunmüller, A.R. y Michael Hattaway (Eds.). The Cambridge Companion to English Renaissance Drama. Cambridge: Cambridge University Press, 91-126.

Holderness, Graham (2003). "Text and Tragedy". En Dutton, Richard and Jean E. Howard (ed.) A Companion to Shakespeare's Work. The Tragedies. Vol. I. Blackwell.

Hornby, Richard (1986). Drama, Metadrama and Perception. Cranbury: Associated University Press.

Hutcheon, Linda (1985). A Theory of Parody. London. Methuen.

Jonson, Ben (2008). Every Man in his Humour. Disponible en: Biblioteca universal: http://biblioteca.org.ar/libros/167070.pdf

— (2003). Volpone. Madrid: Cátedra. 
López Montaner, Ana (2006). El thriller de Antígona. En Hurtado, María de la Luz y Vivian Martínez (comp.) Antología. Dramaturgia chilena del 2000: nuevas escrituras. Santiago: Ed. Cuarto Propio, 91-114.

Kyd, Thomas (2008). La tragedia española. Madrid: Cátedra.

Marlowe, Christopher (2003). The Complete Plays. Penguin Classics.

Margarit, Lucas y Elina Montes (ed). (2017) "Shakespeare's Holinshed, The Cronicle and the Historical Plays Compared. Macbeth". Trad. de Elina Montes. En Shakespeare lector. Lectores de Shakespeare. Buenos Aires: FILO: UBA.

Müller, Heiner (2001). Máquina Hamlet/Cuarteto/Medeamaterial. Buenos Aires: Losada. Murphy, Donna (2013). The Marlowe Shakespeare Continuum. Cambridge: Cambridge Scholars Publishing.

Ovidio, Publio (1994). Heroidas. Madrid: Alianza.

Parra, Nicanor (2004). Lear. Rey \& mendigo. Santiago. Ediciones UDP.

Pavez, Eduardo (s/f). Que no quede ni un rescoldo. Disponible en: http://www.eduardopavezgoye.com/wp-content/uploads/2014/08/Que-no-quede -ni-un-rescoldo-2010-Eduardo-Pavez-Goye.pdf

Radrigán, Juan (2015). La tempestad. Manuscrito, aún sin publicar. Autorización de Flavia Radrigán.

— (2004). Medea mapuche. En Crónicas de amor furioso. Santiago: Ediciones Frontera Sur, 141-155.

Shakespeare, William (2005). A Midsummer Night Dream. King Lear. Hamlet. Otello. Macbeth. Richard III. The Tempest. The Oxford Shakespeare. The Complete Works. Ed. by J. Jowett, W. Montgomery, G. Taylor, S. Wells. Oxford Clarendon Press.

Shapiro, James (2010). Contested Will: Who wrote Shakespeare. London: Faber \& Faber. 